\title{
Diffusion of Telecommunication Services in Turkey
}

\author{
Türkiye'de Telekomünikasyon Hizmetlerinin Yayılımı
}

Mehmet KARAÇUKA ${ }^{1}$, A.Nazif ÇATIK²

\section{ABSTRACT}

This paper evaluates the forecasting ability of alternative product growth models for telecommunication services in Turkey. The variable exponential growth model better explains the diffusion process of fixed line services, suggesting that S-shaped models are not able to model the period of the maturity stage. However, the Gompertz model is superior in explaining the diffusion process of mobile line services. Results suggest that forecasting ability of growth curves depends on the differences in characteristics and the competitive structures of the markets.

Keywords: Telecommunications, forecasting, diffusion of innovations, S-shaped growth curves.

\section{INTRODUCTION}

The diffusion process of telecommunications attracts considerable attention among policy makers, managers and scholars-especially in marketing and economics. One reason is that telecommunication networks are essential elements of techno-social infrastructure for all sorts of economic, social and personal interactions; further, they are considered as important drivers of economic growth and development (Röller and Waverman, 2001). Along with their widespread influence on society, the share of telecommunications in overall economic activity is also increasing rapidly. The recent emergence of new services such as mobile telephony and the internet are transforming not only telecommunication services but almost all economic and social activities in many aspects.

Understanding the diffusion process of new technologies is crucial to strategic planning of economic and social infrastructure. The high dependence of societies on modern telecommunication services makes forecasting for future capacity and infrastructure planning imperative, given the involved ambiguities, time-lag for capacity expansion, and shortening life-cycles. Furthermore, determining main factors of market growth are expected to provide important information for firms and policy makers.

\section{ÖZET}

Bu çalışmada alternatif ürün büyüme modellerinin Türkiye'deki telekomünikasyon hizmetlerini öngörü gücü değerlendirilmiştir. Değişken üstel büyüme modeli sabit hatlardaki yayılma sürecini daha iyi açıklaması, S-şekilli modellerin ürünün olgunluk döneminin modellenmesinde yetersiz kaldıklarını göstermektedir. Ancak, Gompertz modeli mobil hatların yayılma sürecinin açıklanmasında daha üstün görünmektedir. Sonuçlar büyüme eğrilerinin öngörü gücünün, piyasaların karakteristikleri ve rekabetçi yapılarındaki farklılıklara göre değiştiğini göstermektedir.

Anhtar Sözcükler: Telekomünikasyon, öngörü, yeniliklerin yayılımı, S-şekilli büyüme eğrileri

Traditionally, diffusion models have been used in telecommunications for forecasting the demand of a new product, to measure the product lifecycle dynamics, and as a decision tool to make strategic marketing choices (Meade and Islam, 2006; Fildes and Kumar, 2002). Although no consensus exists that agrees upon the best forecasting ability of the various diffusion models, Gruber and Verboven (2001); Rouvinen (2006); Sundqvist, Frank and Puumalainen (2006); and Wu and Chu (2010) suggest that applying an S-shaped diffusion model is the first step to analyze diffusion of telecommunication services. S-shaped (sigmoid) models are based on an assumption that the adoption of a new product in a population is based on the delayed spread of information about new technology; further, the rate of adoption increases through the provision of information. The process of diffusion within the S-shaped curve analogy depicts different stages of product life cycle (Golder and Tellis, 2004). The diffusion starts with an initial slow rise (introduction stage), which then accelerates when customers widely adopt the product or service (take-off stage). This process then increases steadily after it reaches an inflection point onto the saturation level (maturity stage).

\footnotetext{
${ }^{1}$ Assist. Prof., Ege University, Faculty of Economics and Administrative Sciences, Department of Economics, mehmet.karacuka@ege.edu.tr 
The reason why S-shaped models are used widely in the empirical literature is based on the idea that a limited number of innovators in the population adopt the new technology and then the product gets popularity among the imitators by time, such as resembling a spread of epidemic (Meade and Islam, 2006). Based on this legitimate reason, a sigmoid function is usually employed as a first step to estimate the effects of various factors on telecommunications demand and user base. Dekimpe, Parker, and Sarvary (1998) find that social system size and adoption ceiling are the most critical factors in the diffusion process of mobile telecommunications, based on Bass model that covers a sample of 184 countries between 1979 and 1992. Gruber and Verboven (2001) use logistic curve to analyze diffusion of mobile telephony in European Union and find that technological progress dominates market structure between 1984 and 1997.

Sundqvist et al. (2005) in another cross-section study using Bass model find that income and geographical proximity to the innovation centre have positive effects in telecommunications between 1981 and 2000. Rouvinen (2006) finds that diffusion speed of telecommunications is not significantly different between developed and developing countries based on an analysis that covers 200 countries between 1992 and 2000. In single country studies, Frank (2004) finds that network coverage is the most influential factor in the diffusion of mobile phones in Finland, based on logistic diffusion function estimation between 1981 and 1998. Lee and Cho (2007) find that income growth was the most significant factor in Korea between 1984 and 2002. This study, comparing ARIMA and logistic models concludes that logistic model fits the data better than ARIMA models. Meade and Islam (2001) compare 17 growth models based on time series and find that models that use fewer variables such as Logistic, Gompertz and Bass models provide better estimates and more forecast accuracy.

Other studies comparing the best fit models include Wu and Chu (2010) for Taiwan; Botelho and Pinto (2004) for Portugal; Michalakelis et al. (2008) for Greece; and Gamboa and Otero (2009) for Colombia. Botelho and Pinto (2004) find that diffusion is $\mathrm{S}$-shaped and is consistent with a logistic function for Portugal. Their results imply that the rate of diffusion is closer to symmetric, and expected saturation level is $95 \%$ penetration rate in Portuegese mobile telecommunications market. Gamboa and Otero (2009) find that the logistic model characterizes the pattern of diffusion of mobile telecommunications in Colombia. They estimate saturation level as 103.7.

Michalakelis et al. (2008) find a saturation level between 111-126\% for Greece and considers the Gompertz model as the most appropriate model for forecasting, based on MAPE values, although this model fails in estimation and Logistic model fits the actual data better. This finding is in line with $\mathrm{Wu}$ and Chu (2010) that finds different models may be superior in different stages of product life cycles, and the best fitting models may be inferior in forecasting, as argued by Meade and Islam (1998). Wu and Chu (2010) find that the Gompertz model outperforms the other models before diffusion take-off, and the Logistic model is superior after inflection and over the aggregate range of the diffusion. They find that saturation levels vary between 104.8 and 105.5

Telecommunication markets in Turkey provide an interesting case for the comparison of various diffusion models. Fixed line services in Turkey suffered a lack of necessary investments for decades, which resulted in low innovation due to the presence of a state monopoly (Turk Telekom) until 2005. For a long time, telecommunications services had been regarded as luxury consumption in Turkey and in 1950 number of subscribers were only 58 thousand, which corresponds to a penetration rate around 0.3 $\%$, due to the lack of necessary infrastructure. Even in 1980 the number of subscribers was barely above 1 million and penetration rate was only $2.45 \%$. After 1980 's, the change in economic policy also increased infrastructural investment and the number of subscribers reached about 7 million in 1990, and 18.4 million in 2000, with penetration rates of $14.5 \%$ and $27.1 \%$ in respective years. This increasing trend slowed down after the year 2000, due to mobile telephony substitution, and maximum level of subscribers was observed as 19.1 million in 2004 with a penetration rate around $27 \%$. Since then, the number of subscribers has been continuously decreasing. At the end of year 2011, total number of subcribers for fixed line services was 15.2 million and penetration rate was $20.6 \%$ (ICTA, 2012).

Unlike fixed line, the diffusion of mobile telecommunications started rather quickly. In 1994 when the second generation mobile services became available, number of subscribers was 82 thousand at the end of that year and increased to 15 million by the end of 2000, corresponding to a penetration rate of $22.1 \%$. The number of subscribers and penetration rates increased until the year 2007 in which number 
portability has been implemented. At present, the number of adopters of mobile telecommunications has started increasing, whereas the cumulative subscribers in fixed line services have been declining. In this study, as an alternative to conventional diffusion models, we consider the decline in fixed line telecommunications and employ the variable exponential growth model. This model has more flexible assumptions (Su and Han, 1998), and able to track a decline in the diffusion process.

The aim of this study is to compare the forecasting ability of diffusion models for telecommunication services that are on different life-cycle spans and in different market structures. The results suggest that forecasting ability of diffusion models differ across market structures and the stage of diffusion process. To our best knowledge, this study is the first that aims to empirically analyze the diffusion process of telecommunications and to evaluate the forecasting power of diffusion models for Turkey.

The remainder of this paper is organized as follows: the next section gives an overview of the most widely used S-shaped diffusion curves and the variable exponential growth model, empirical results are presented in section 3, and finally, conclusions are found in the last section.

\section{OVERVIEW OF DIFFUSION MODELS}

The cumulative spread of an innovation or product across markets is usually defined by a sigmoid or an S-shaped growth pattern (Geroski, 2000). The reason behind a sigmoid pattern is that not all consumers adopt a new product immediately; hence, their perceptions of the net utility of consumption differ due to the characteristics of both the product and individuals. Therefore, diffusion starts slowly and grows exponentially till the peak level where the market is also saturated.

Using diffusion models to explain the S-shaped nature of a new product's diffusion curve have been common in the literature over a long period. The central question of these models pertains to which factors determine the diffusion speed of a new product of which potential adopters' decisions occur with a delay, yet they exhibit a successive increase of the adopters over a time. The main drivers of diffusion can be categorized as internal, external and mixed influence factors (Bass, Krishnan and Jain, 1994). The internal influence can be described as a result of interaction within a social system wherein individuals affect decisions of one another. External influen$c e$, on the other hand, represents factors indepen- dent from social relations which provide necessary information (mass media) or promote a product. Mixed factors are combination of both. Several theories have been developed to model diffusion patterns of a new product that depict successive increases in the number of the adopters within given sets of prospective adopters. Among others, the Bass, Gompertz and Logistic are the most widely used models to predict the future trend of a new technology.

The Bass model (Bass, 1969), which is a pioneer formulation of the diffusion of a new product is based on mixed-influence factors that affect the cumulative number of adoptions of a new technology at time $(\mathrm{t})$, starts with a population of $\mathrm{m}$ potential adopters:

$$
N(t)=m F(t)
$$

For each potential adopter, the time to adoption is a random variable with a distribution $\mathrm{F}(\mathrm{t})$ and density $f(t)$, such that the hazard rate depicts the conditional probability of a purchase in a time interval $(t, t+\Delta)$ if the purchase has not occurred before $t$ ( Chandrasekaran and Tellis, 2007):

$$
\frac{f(t)}{1-F(t)}=p+q F(t) ; f(t)=(p+q F(t))(1-F(t))
$$

where parameters $p$ and $q$ represent the coefficient of innovation (external factors) and imitation (internal factors such as interpersonal channels of information), respectively.

Assuming that $F(t)$ is differentiable (2) is equivalent to

$$
\frac{d F(t)}{d t}=p+(q-p) F(t)-q F(t),
$$

when the sales and the cumulative sales of the new product are denoted by $S(t)$ and $Y(t)$, respectively, the number of sales at time $t$ can be can be derived from (1) and (2) as follows:

$$
\begin{aligned}
S(t) & =p m+(q-p) m F(t)-q m(F(t))^{2} \\
& =p m+(q-p) Y(t)-\frac{q}{m} Y(t)^{2^{\prime}}
\end{aligned}
$$

and from (2) and (3) a Bass model is expressed as the following (5) differential equation

$$
d(t)=d(F) /\left(p+(q-p) F-q F^{2}\right) .
$$

Hence, the cumulative sales (6) can be expressed as follows:

$$
F(t)=m\left[\left(1-e^{-(p+q) t}\right) /\left(1+(q / p) e^{-(p+q) t}\right)\right] .
$$

Epidemic diffusion models that rely solely on internal factors in the diffusion process are also common in the literature. Following the seminal paper 
of Grichelles (1957), which modeled the diffusion of hybrid corn in the United States; these models have been used in many studies (Mansfield 1961; Chow, 1967) which confirms the validity of this approach in various sectors. Gruber $(2005,149)$ also argues that these models fit the diffusion path of many innovations, including mobile telecommunications, given the impact of network effects.

One diffusion model is the logistic function, which assumes the contagion hypothesis such that diffusion occurs only through social interactions. Lekvall and Wahlbin $(1973,182)$ describe the logistic model based on the assumption that the diffusion rate at a given point is proportional to the remaining distance to some determined saturation level as well as to the instantaneously attained diffusion level. The logistic function is formulated as follows ( Mahajan and Peterson 1985, 15):

$$
\frac{d F(t)}{d t}=b F(t)[(m-F(t)],
$$

where $F(t)$ and $m$ has the previous meanings, and the parameter $\alpha$ and $\beta$ define the location of the diffusion curve and diffusion speed respectively. The solution of this first-order differential equation is (8) yields the following function:

$$
F(t)=\frac{m}{1+e^{(\alpha+\beta t)}} .
$$

The Gompertz model is another epidemic model. It also takes only internal factors into account for the diffusion process. The Gompertz curve-which also has an S-shape pattern-can be expressed as:

$$
F(t)=m \cdot e^{-\alpha \cdot e^{-\beta t}} \text {. }
$$

The main difference between the logistic curve and the Gompertz curve can be attributed to their respective inflection points. The Gompertz curve reaches the maximum rate of growth when total number of adopters is about $37 \%$ and is asymmetric to the inflection point. However, the maximum rate is reached by the logistics curve when the total number is $50 \%$ of the potential market and symmetric to its inflection point.

S-shaped diffusion models depict the diffusion process of a product between the introduction and saturation stages. However, fixed line service in Turkey has reached the saturation level and started to steadily decline. To address declining part of the diffusion curve we employ the variable exponential model, proposed by Su and Han (1998), which defines exponential growth of adopters of a product by a polynomial of degree $\mathrm{n}-\mathrm{l}$ :

$$
F(t)=a \cdot e^{\beta_{1} t^{n-1}+\beta_{2} t^{n-2}+\ldots+\beta_{n-1} t} .
$$

Su and Han (1998) argue that this model is more convincing than the logistic model because it provides a better fit by relaxing explicit assumptions on symmetry and inflection points. In this formulation the parameter $\beta$, continuous growth rate, is not a constant in contrast to logistic growth model but a variable expressed by a polynomial of degree $n-2$. The variable exponent may get larger or smaller, and even become a negative number as the time dimension increases.

\section{ESTIMATION METHOD AND EMPIRICAL RESULTS}

\subsection{Estimation Method}

To estimate saturation levels and growth rates in the diffusion process of telecommunication services, we use annual subscriber base data in Turkey between 1950 and 2009 for fixed line services and monthly data between January 1995 and December 2007 for mobile line services. The selected period is based on the availability of the data, of which monthly statistics of mobile subscriber base was not available to us after 2007. The data set is collected from an OECD database and the Telecommunications Authority (TA) of Turkey.

The empirical models to be estimated for each service can be expressed in nonlinear forms after adding disturbance terms to equations (6), (8), (9) and (10) such that:

$$
X_{t}=F(t ; \Phi)+\varepsilon_{t} .
$$

In equation (11), $\left(X_{t}\right)$ represents the cumulative number of subscribers for fixed and mobile separately. is the nonlinear cumulative distribution function subject to the estimation, $\Phi\left(\Phi=\Phi_{1}, \Phi_{2}, \ldots, \Phi_{k}\right)$ is a k-dimensional vector of parameters to be estimated, and $\varepsilon_{t}$ denotes the error term.

The common approaches to estimate the parameters of diffusion models are the nonlinear least squares (NLS) and maximum likelihood (ML) methods (Meade and Islam, 2006). Srinivasan and Mason (1986) find that $\mathrm{ML}$ underestimates the standard errors of the estimated parameters and suggests that the NLS approach is more appropriate for diffusion models in which cumulative adoption can be expressed as an explicit function of time. This argument is also supported by Jain and Rao (1990); however, Van den Bulte and Lilien (1997) indicate a downward bias in estimated saturation levels with too small of a sample size. Because we have an adequate number of observations given the previous studies, NLS method is used in the estimation of diffusion models. 


\subsection{Empirical Results}

The study takes three steps in its estimation strategy. First, to find out which model gives the best fit to our data, the study estimates growth models using the full sample range. Second, the models are re-estimated using samples 1950-2006 for the fixed line and 1986-2006 for the mobile line services, and the rest of the data is reserved to evaluate out-of sample forecasting performances. Finally, after determining the models with the highest forecasting accuracy, we use those models to forecast the future values of subscribers.

Table 1: Estimation Results for Diffusion Models

\begin{tabular}{|c|c|c|c|c|c|c|}
\hline \multirow{2}{*}{} & \multicolumn{3}{|c|}{ Fixed Line } & \multicolumn{3}{c|}{ Mobile Line } \\
& \multicolumn{3}{|c|}{ SAMPLE: 1950-2009 } & \multicolumn{2}{c|}{ SAMPLE: 1995:1 -2007:12 } \\
\hline & Bass & Gompertz & Logistic & Bass & Gompertz & Logistic \\
\hline & 20824.610 & 21042.710 & 19766.920 & 109997.600 & 113113.200 & 101568.100 \\
\hline$p$ & $(69.067)$ & $(40.685)$ & $(91.365)$ & $(14.145)$ & $(18.367)$ & $(17.020)$ \\
\hline & 0.00001 & & & 0.00058 & & \\
\hline$q$ & $(3.066)$ & & & $(26.863)$ & & \\
\hline$\alpha$ & 0.248 & & & 0.025 & & \\
\hline & $(27.116)$ & & & $(23.811)$ & & \\
\hline$\beta_{1}$ & & 903.466 & 113886.600 & & 6.637 & 65.416 \\
\hline & & 0.169 & 0.276 & & $(35.391)$ & $(21.889)$ \\
& & $(15.999)$ & $(30.918)$ & & $(23.203)$ & $(31.876)$ \\
\hline $\mathrm{R}^{2}$ & 0.996 & 0.992 & 0.997 & 0.994 & 0.994 & 0.990 \\
\hline Log likelihood & -439.302 & -454.925 & -429.830 & -1365.964 & -1366.783 & -1406.890 \\
\hline AIC & 15.252 & 15.791 & 14.925 & 17.439 & 17.449 & 17.960 \\
\hline
\end{tabular}

Note: $t$-statistics are given in parenthesis. All variables are significant at $1 \%$ significance level.

Table 2: Variable Exponential Growth Curve Models

\begin{tabular}{|c|c|c|}
\hline & Fixed Line & Mobile Line \\
\hline & Sample: 19502009 & Sample 1995:1-2007:12 \\
\hline \multirow[t]{2}{*}{$\alpha$} & 794.726 & 688.846 \\
\hline & $(2.905)$ & $(10.171)$ \\
\hline \multirow[t]{2}{*}{$\beta_{1}$} & -0.630 & 0.048 \\
\hline & $(-9.606)$ & $(28.620)$ \\
\hline \multirow[t]{2}{*}{$\beta_{2}$} & 0.037 & -0.0001 \\
\hline & $(9.996)$ & $(-17.662)$ \\
\hline \multirow[t]{2}{*}{$\beta_{3}$} & -0.0007 & \\
\hline & $(-8.536)$ & \\
\hline \multirow[t]{2}{*}{$\beta_{4}$} & 0.000004 & \\
\hline & $(6.9263)$ & \\
\hline $\mathrm{R}^{2}$ & 0.998 & 0.993 \\
\hline Log likelihood & -414.20 & -1378.41 \\
\hline AIC & 14.455 & 17.598 \\
\hline
\end{tabular}

Note: t-statistics are given in parenthesis. All variables are significant at $1 \%$ significance level. 
The results for the estimated parameters of different diffusion models for fixed and mobile line subscriptions are presented in Tables 1 and 2. To evaluate the forecasting accuracy of the models, Mean Absolute Error (MAE) and Root-Mean Squared Error (RMSE) are calculated as follows:

$$
\begin{aligned}
& R M S E=\sqrt{\sum_{t=T+1}^{T+h} \frac{\left(\hat{X}_{t}-X_{t}\right)^{2}}{h}} \\
& M A E=\sum_{t=T+1}^{T+h} \frac{\left|\hat{X}_{t}-X_{t}\right|}{h}
\end{aligned}
$$

Tables 3 and 4 report the RMSE and MAE values used to evaluate the diffusion models in terms of insample fit and out-of-sample forecasting accuracy for the fixed and mobile lines.

Table 3: Forecasting Performance of the Growth Models: Fixed Line

\begin{tabular}{|c|c|c|c|c|c|c|c|c|}
\hline & \multicolumn{5}{|c|}{ In-Sample Fit } & \multicolumn{3}{c|}{1 Year Ahead } \\
\hline & Bass & Gompertz & Logistic & Variable Exp. & Bass & Gompertz & Logistic & Variable Exp. \\
\hline RMSE & 784.580 & 755.999 & 551.295 & 293.903 & 492.750 & 631.459 & 410.473 & 297.815 \\
\hline MAE & 463.288 & 595.868 & 413.057 & 241.179 & 347.674 & 490.144 & 319.502 & 249.562 \\
\hline & \multicolumn{3}{|c|}{2 Years Ahead } & \multicolumn{5}{c|}{3 Years Ahead } \\
\hline & Bass & Gompertz & Logistic & Variable Exp. & Bass & Gompertz & Logistic & Variable Exp. \\
\hline RMSE & 627.072 & 741.490 & 507.833 & 298.519 & 793.814 & 894.042 & 643.368 & 301.170 \\
\hline MAE & 392.686 & 533.557 & 353.631 & 251.042 & 449.843 & 590.323 & 399.429 & 254.017 \\
\hline
\end{tabular}

Table 4: Forecasting Performance of the Growth Models: Mobile Line

\begin{tabular}{|c|c|c|c|c|c|c|c|c|c|c|c|c|c|}
\hline & \multicolumn{5}{|c|}{ In-Sample Fit } & \multicolumn{3}{c|}{1 Month Ahead } & \multicolumn{3}{c|}{3 Months Ahead } \\
\hline & Bass & Gompertz & Logistic & Variable Exp. & Bass & Gompertz & Logistic & Variable Exp. & Bass & Gompertz & Logistic & Variable Exp. \\
\hline RMSE & 1453.123 & 1323.737 & 1885.866 & 1572.992 & 1483.098 & 1325.090 & 1743.050 & 1542.359 & 1478.132 & 1335.038 & 1751.801 & 1546.822 \\
\hline MAE & 1192.358 & 1138.352 & 1606.655 & 1352.756 & 1233.236 & 1119.327 & 1589.325 & 1386.248 & 1225.927 & 1127.857 & 1597.170 & 1391.085 \\
\hline & \multicolumn{3}{|c|}{6 Months Ahead } & \multicolumn{3}{|c|}{9 Months Ahead } & \multicolumn{4}{c|}{12 Months Ahead } \\
\hline & Bass & Gompertz & Logistic & Variable Exp. & Bass & Gompertz & Logistic & Variable Exp. & Bass & Gompertz & Logistic & Variable Exp. \\
\hline RMSE & 1463.998 & 1380.292 & 1799.682 & 1576.656 & 1451.545 & 1333.978 & 1886.824 & 1638.067 & 1441.470 & 1343.517 & 2020.160 & 1739.481 \\
\hline MAE & 1207.472 & 1161.414 & 1632.972 & 1416.124 & 1194.166 & 1168.756 & 1687.503 & 1457.563 & 1185.856 & 1180.11 & 1761.175 & 1516.289 \\
\hline
\end{tabular}

According to the Bass, Gompertz, Logistic and variable exponential growth models, the estimated saturation levels for fixed line subscriptions are found as 20.82, 21.04, 19.76 and 19.32 million, respectively. The coefficient of innovation ( $p$ ) in the Bass model, which describes the effects of external factors that are outside of interpersonal relations, has a very small value for the fixed lines. On the other hand, the internal effects (q) seem to dominate the diffusion process both in fixed and mobile lines, which is an indicator of strong network effects.

The variable exponential growth model predicts the saturation level more accurately as it provides a closer upper bound value to the actual data, which reached a saturation level of 19.125 millions in 2004 . The variable exponential growth model also exhibits the best in-sample and out-of-sample forecasting accuracy for the fixed line (see Table 3 and Figure 1). This may not be surprising because this model, unlike the conventional S-shaped models, ably covers the diffusion process after the saturation stage where the number of adopters starts to decline. However, this result remains the same when the models are estimated with the sample up to the saturation level.

The estimated saturation levels for mobile services differ across the models. The Bass model estimates the saturation level as 109.9 million; the coefficient of $(\mathrm{m})$ is lowest with 101.6 million for the logistic model and highest for the Gompertz model with a value of 113.1 million. In terms of population in 2007, the saturation point of penetration rates for mobile lines correspond to around $144 \%$ for the Bass, 185 $\%$ for the Gompertz and $156 \%$ for the Logistic models. One can compare these levels with the average penetration rate of $106 \%$ of the European Union, wherein the highest rates are seen in Luxembourg (155\%), Lithuania (139\%) and Italy (134\%) in 2006 (EUROSTAT; 2012). These values show that multihoming (some consumers get more than one line) is a common observation in mobile telecommunication 


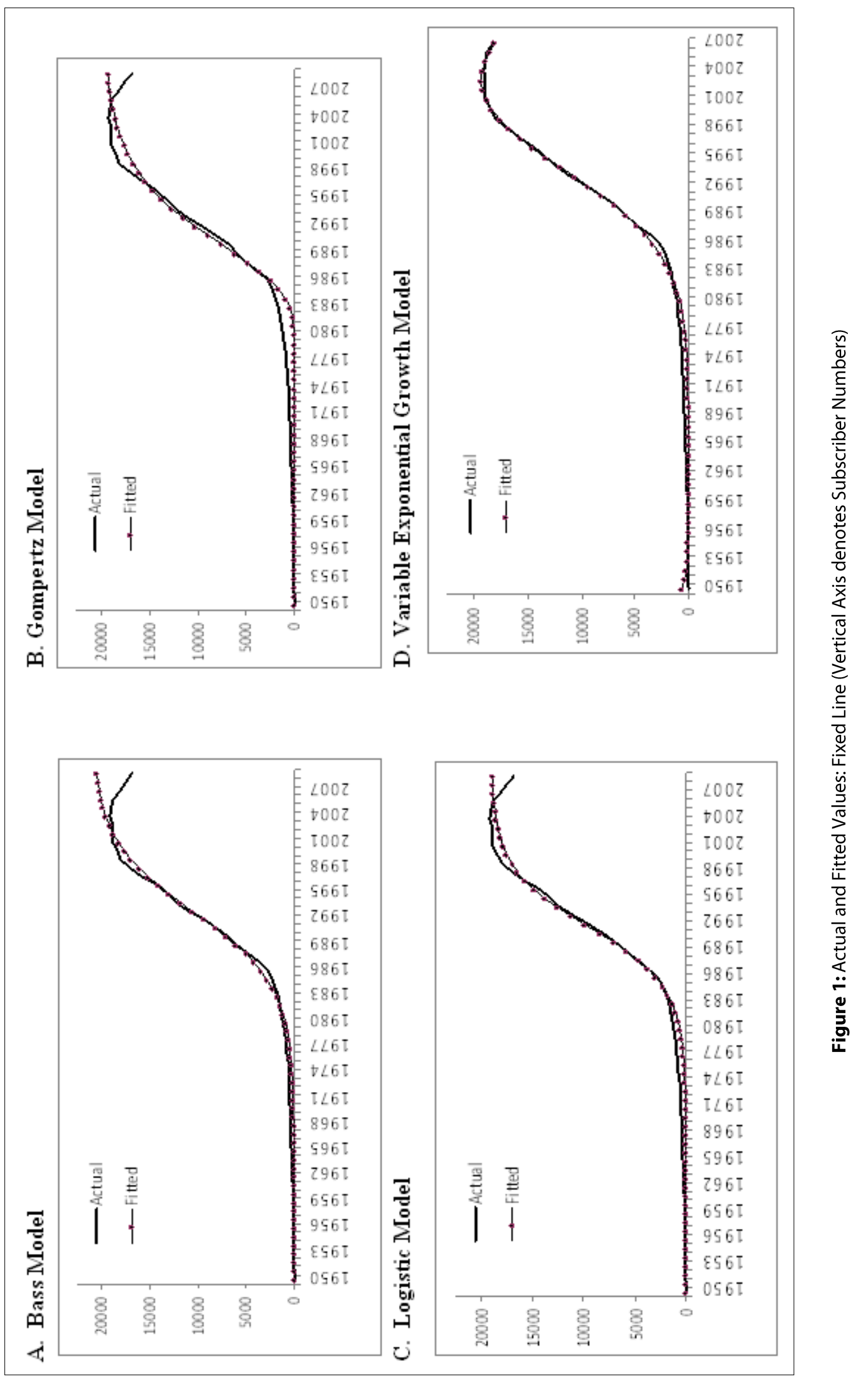




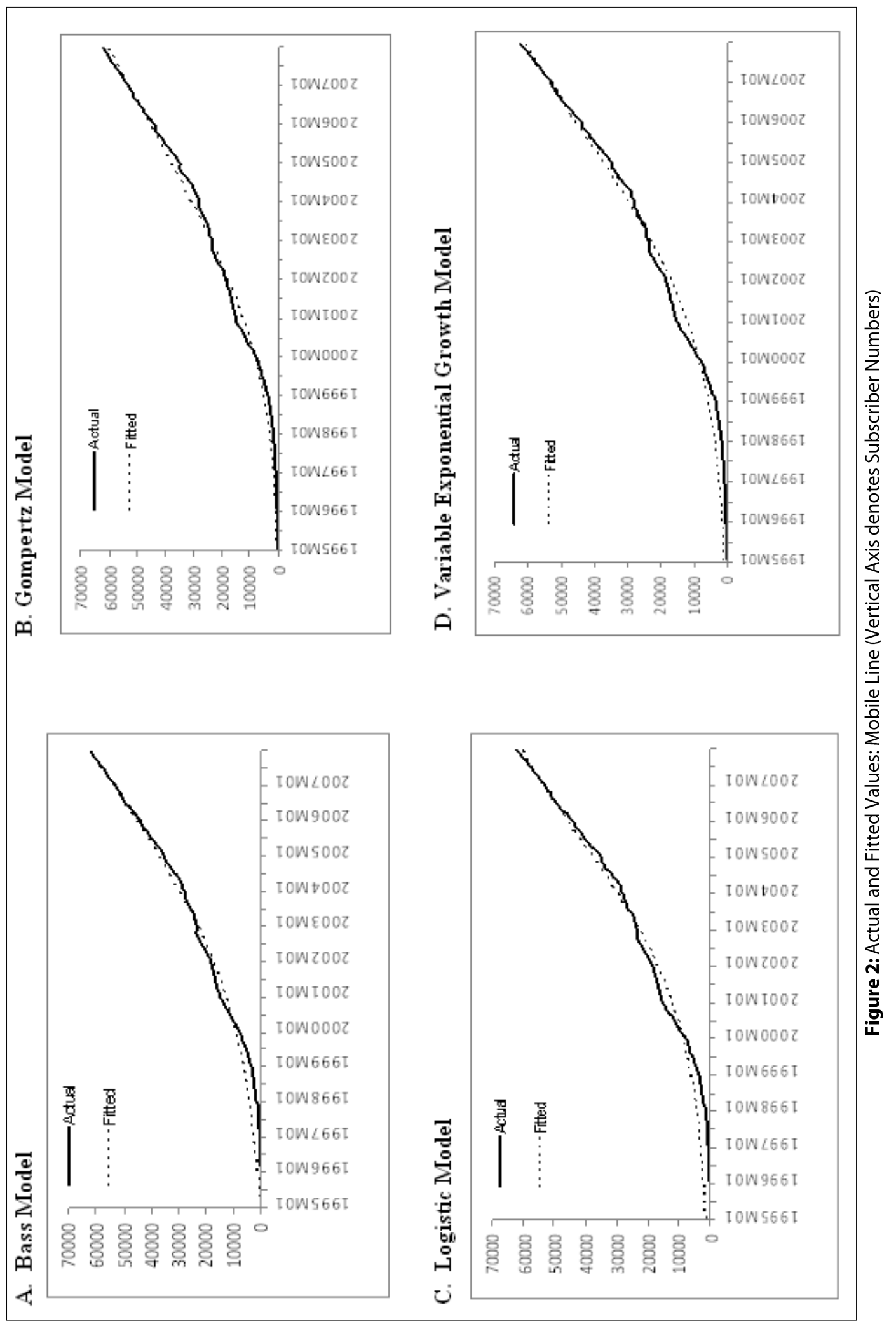


markets and there is a wide gap in Turkey for the networks to increase their subscriber bases.

As Table 1 reports, the coefficient of ( $p$ ) in the Bass model for the mobile line is considerably higher than that of the fixed line, indicating that external factors play a bigger role in mobile line services. In other words, the Bass model, including the external factors, improves the fit of the logistic function for the mobile services in Turkey. When different models are compared in Table 3, the Gompertz model gives the minimum RMSE and MAE values for in-sample and out-of-sample forecasts in the mobile lines. Although all the models employed for the estimation and forecasting have similar patterns, the underlying dynamics of the Gompertz model requires further analysis, as this model better corresponds to the actual data. First of all, the Gompertz curve by formulation, as described above, is asymmetrical around the inflection point, whereas the Logistic model is symmetrical. The difference between the inflection points of different curves implies that the Gompertz model allows more growth opportunity (63\%) after the inflection point, whereas this opportunity is smaller (50\%) for the Logistic model. Another implication of the symmetry assumption of the Logistic model is that the diffusion remains a function of users and non-users after the inflection point, whereas the Gompertz model describes the diffusion as a function of non-users (Wu and Chu, 2009).

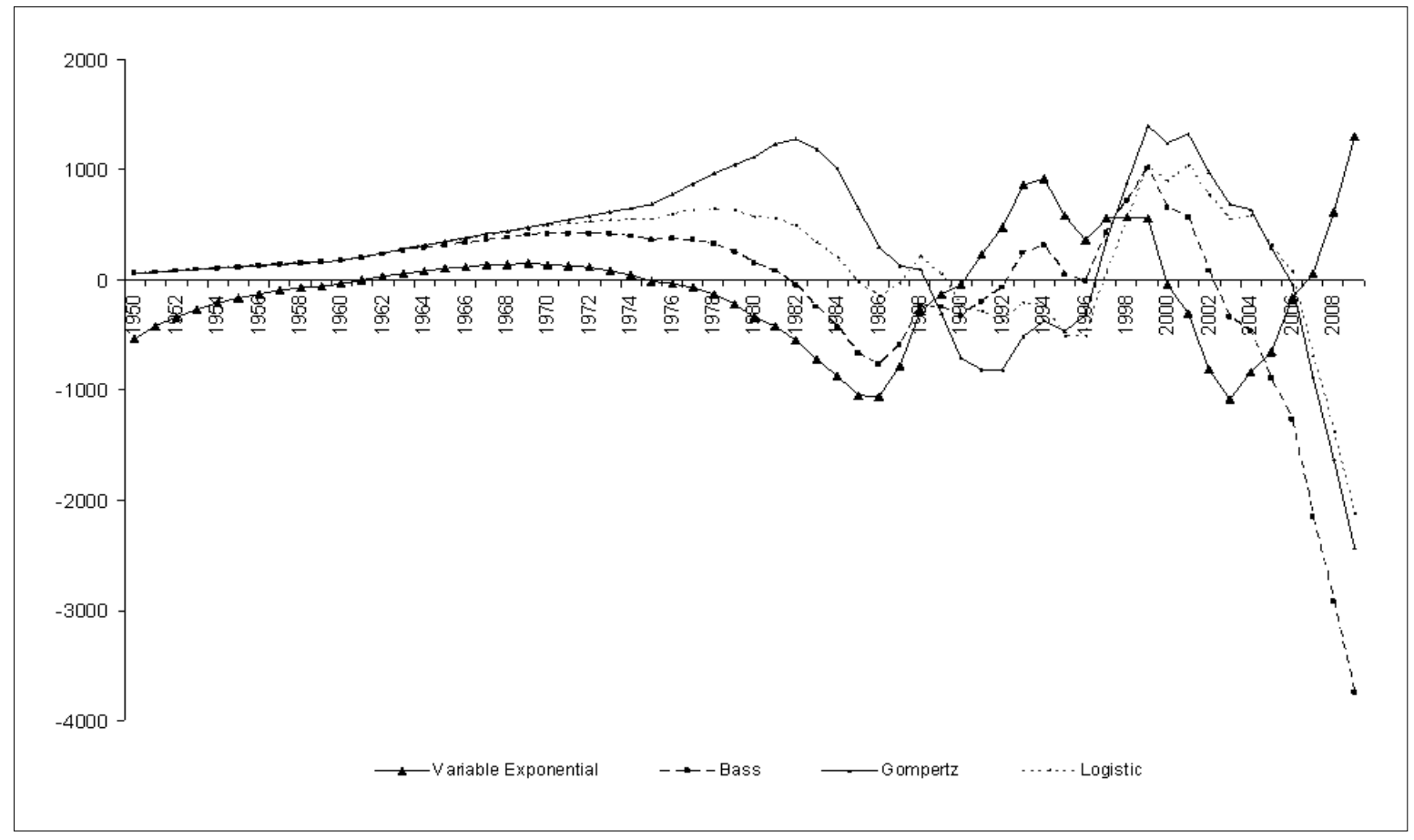

Figure 3: Residuals of the Diffusion Models: Fixed line 


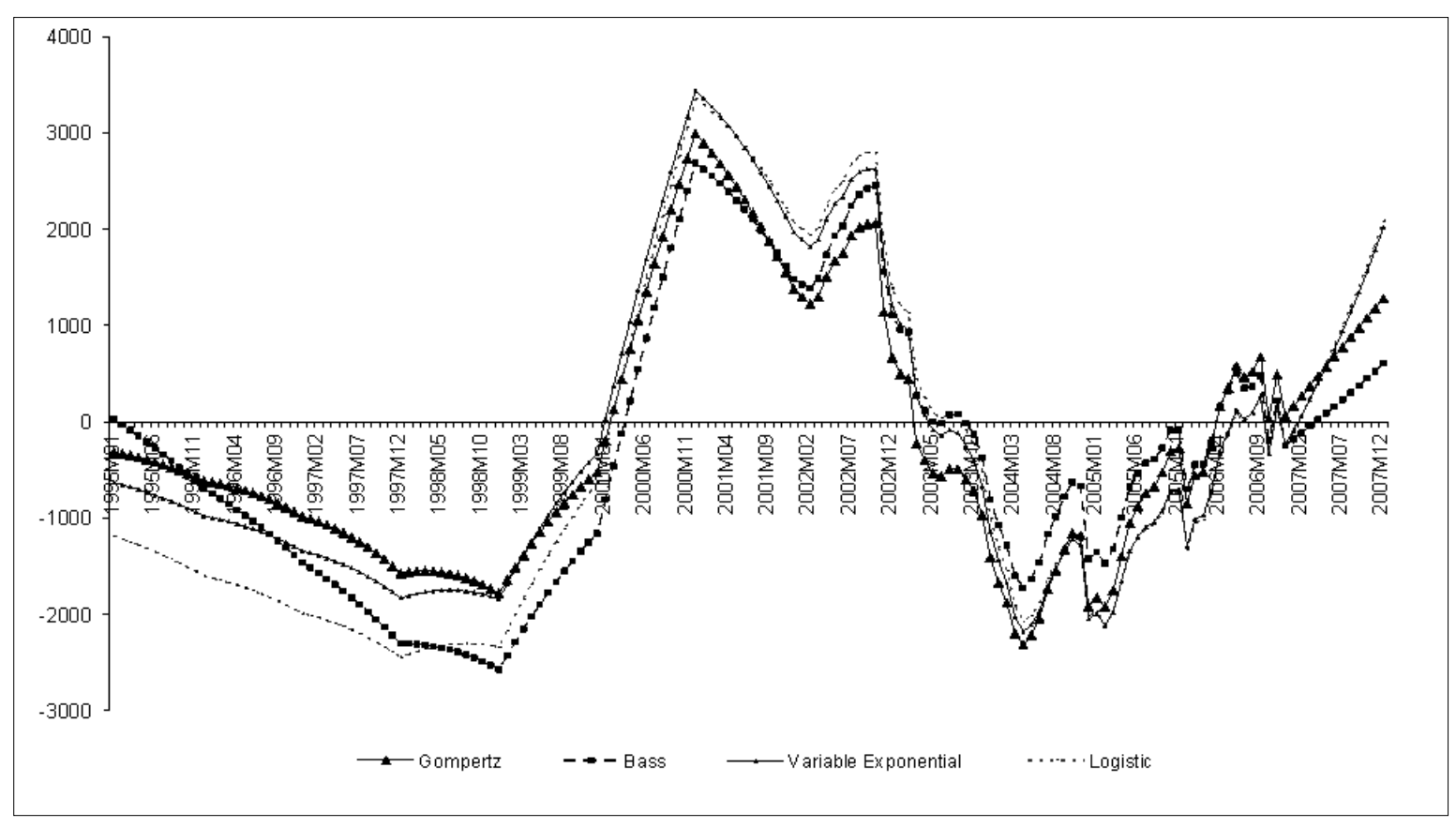

Figure 4: Residuals of the Diffusion Models: Mobile Line

To provide a better insight on the in-sample fit of the growth models under the different stages of diffusion process, residuals of the estimates are reported in Figures 3 and 4 for the fixed and mobile lines, respectively. For both fixed and mobile lines, the variable exponential growth model gives the best fitted values in the introduction stages of the products till the take-off stage. However, between the take-off and maturity stages (1980-2000), the logistic model outperforms the others in the fixed line services. For the mobile line services, the take-off stage starts in 2000, and the Bass model gives better fitted values until 2004, which is the period of the increased competition due to the entrance of two new firms into the market. The Gompertz model is superior after 2004. The better fitted models in different stages and services suggest that the growth was driven by internal factors in fixed line whereas the external factors have played an important role in mobile lines.

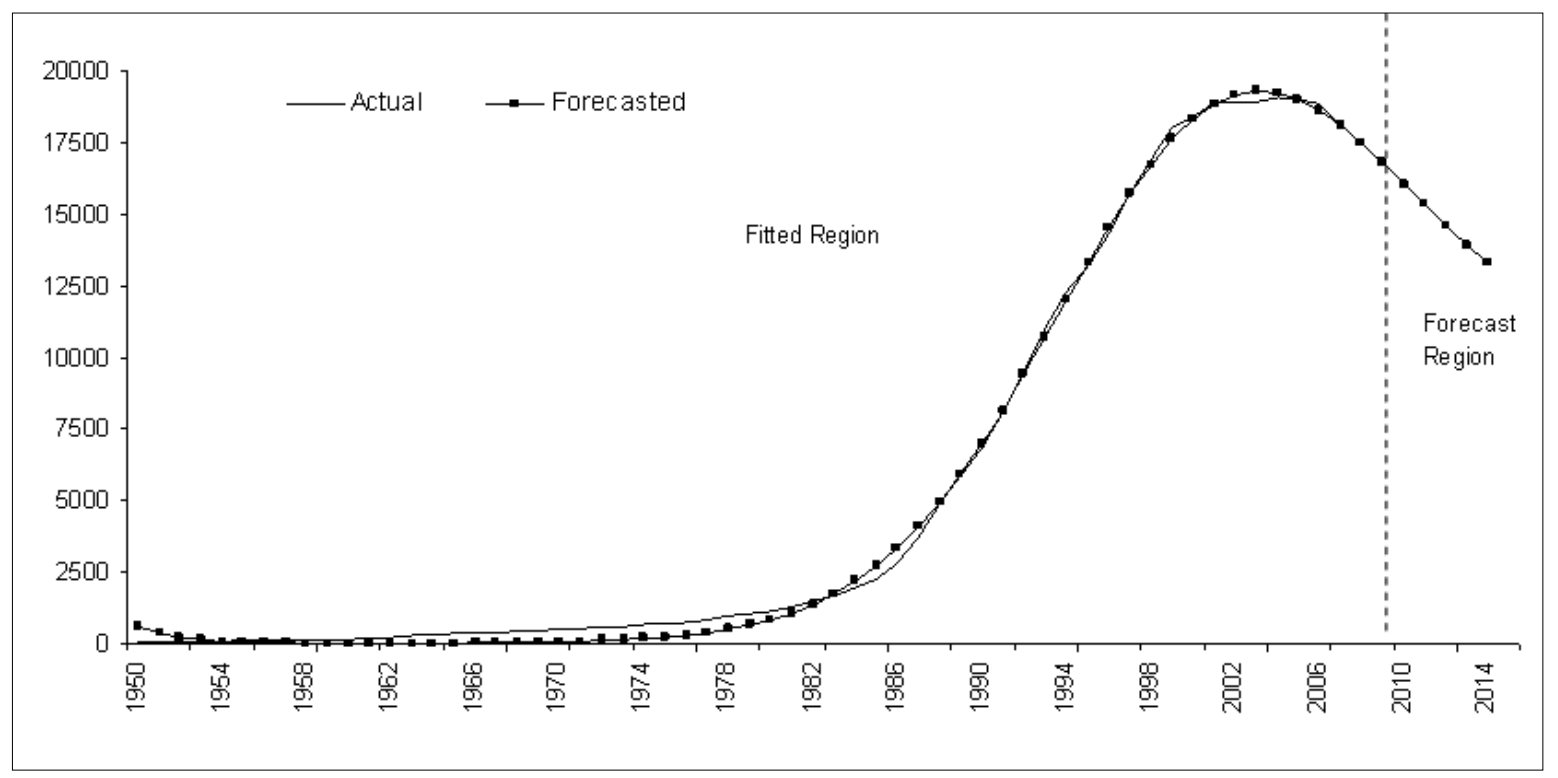

Figure 5: Future Value Forecasts of Variable Exponential Growth Model: Fixed Line 2009-2015 (Subscriber Numbers) 


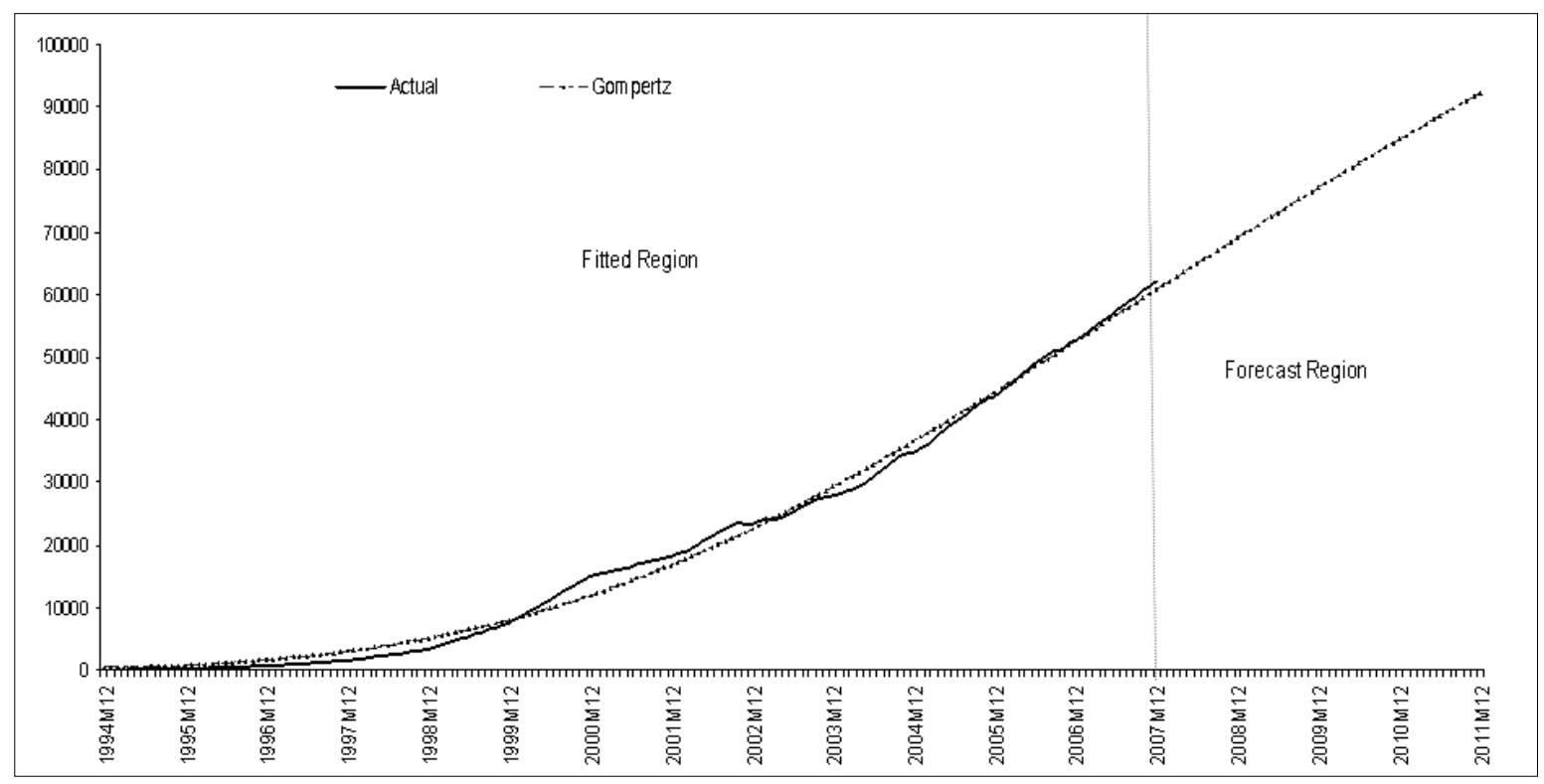

Figure 6: Future Value Forecasts of Gompertz Model: Mobile Line 2008:1-2011:12 (Subscriber Numbers)

After determining the models with the best outof-sample forecasting performance as variable exponential growth and Gompertz models for fixed and mobile lines respectively, those models are used to forecast the future values. The forecasted values of the fixed line in Figure 5 show that the number of fixed line subscribers will decrease gradually and will be around 12.770 million by 2015 . Forecasts for the mobile line indicate that the mobile markets will continue to grow, although in a decreasing rate, suggesting that the number of subscribers for mobile line services by the year 2012 will rise to 92.2 million (see Figure 6).

\section{CONCLUSION}

This study analyzes the diffusion process of fixed and mobile lines using subscriber data in Turkey with different growth curves. The results show that these services have different growth patterns that are explainable by different diffusion curves.

For fixed line services, where the saturation level was reached during the estimation period, the variable exponential growth curve fits better in to the diffusion process. One reason for the failing of conventional S-shaped models is that by their formulation, they are not able to model periods where the number of adopters starts to decline. However, the variable exponential growth curve also fits and forecasts better when the product achieves the maturity stage. On the other hand, for mobile lines, the Gompertz model has better explanatory power. As expected, models with the best in-sample fit give also the best out-of-sample forecasting performances. The future forecasted values obtained from those models predict that the trend will be decreasing for the fixed line, whereas increasing for the mobile services.

The explanatory powers of models differ with characteristics of the markets and the life-cycle spans of a product. The logistic model better explains the take-off stage of fixed line services, whereas the variable exponential growth model is superior for the period of maturation and decline. However, the Bass model outperforms the others in mobile lines for the beginning of take-off stage (2000-2004 period) when two new firms entered the market. The main characteristic of the market in this period is the increased competition that forced the firms to rely more on mass media and promotions. This stage ended in 2004 when two firms bankrupted and exited the market.

In this study we find that internal effects dominates the diffusion process both in fixed and mobile lines, which is an indicator of strong network effects. Strong network effects in telecommunication technologies impose policy makers and managers some responsibilities both in terms of diffusion of innovations and for sustaining competition in markets. New technologies should be promoted by governments at least until they achieve a critical mass. Managerial practises should consider the value of additional subscriber as they have potentials to attract more consumers. However, strong network effects may also distort competition by tipping the market to 
one network that leads "winner takes all", even with an inferior technology, and limit the potential market growth. Regulatory organizations should implement policy measures to prevent the abuse of market power.

Out of data results of exponential growth model also provide accurate predictions for the numbers of fixed line subscribers. This model predicts that there will be 16.06 million subscribers in 2010 and 15.33 million subscribers in 2011, which are very close to the observed actual numbers ( 16.20 million in 2010, and 15.20 million in 2011) for these years. However, we observe a divergence of observed and forecast values for mobile. We argue that important policy changes after 2007, such as number portability and interconnection rates have affected the mobile market, limiting the number of multihomers. In mobile markets, the number of subscribers decreased consecutively for three years in 2008, 2009 and 2010, and started to increase in 2011. Out of data forecasts in such cases that involve a structural change fail to yield reliable predictions.

According to Turkish case, we see that there is no single model that can capture, and forecast the whole life cycle of a product. Different models may be superior depending on the life span of an innovation. Furthermore, competition and market structure have important effects in market growth. The rapid increase and unexpected decrease in the subscriber numbers in Turkish mobile markets after procompetitive reforms confirms this observation. Geroski (2000) argues that too much competition may slow down diffusion. Such a case was also observed in Greece, when the mobile market was transformed to oligopoly from duopoly as reported by Michalakelis et al. (2008). However, the slowdown, even the contraction, may not result social welfare loses when the decrease is a result of elimination of multihomers in telecommunications. Doganoglu and Wright (2006) show that multihoming weakens comptetion as multihoming and compatibility are substitutes. They also find that multihoming imposes costs that firms do not internalize. Turkish case emphasize more on this argument and future studies on telecommunication markets should focus more on the effects of competition and multihoming on market growth. These arguments emphasize once more the importance of regulatory institutions to achieve welfare increases as a result of a "healthy" growth and diffusion of telecommunications. 


\section{REFERENCES}

Bass, F.M. (1969) "A New Product Growth for Model Consumer Durables" Management Science, 15(5):215-227.

Bass, F.M., Krishnan, T.V ve Jain, D. (1994) "Why The Bass Model Fits Without Decision Variables" Marketing Science, 13(3): 203-223.

Botelho, A. ve Pinto, L.C. (2004) "The Diffusion of Cellular Phones in Portugal" Telecommunications Policy, 28(5/6), 427-437.

Chandrasekaran, D. ve Tellis, G.J. (2007) "A Critical Review of Marketing Research on Diffusion of New Products" Naresh et al. (eds.) Review of Marketing Research, Armonk NY, M.E. Sharpe Press.

Chow, G.C. (1967) "Technological Change and the Demand for Computers" American Economic Review, 57(5): 1117-1130.

Collopy, F. ve Armstrong, J.S. (1992) "RuleBased Forecasting: Development and Validation of an Expert Systems Approach to Combining Time Series Extrapolations" Marketing Science, 38(10):1394-1414.

Dekimpe, M.G., Parker, P.M. ve Sarvary, M. (1998) "Staged Estimation of International Diffusion Models" Technological Forecasting and Social Change; 57 (1-2): 105-132.

Doganoglu, T.ve Grzybowski, L. (2007) "Estimating Network Effects in Mobile Telephony in Germany" Information Economics and Policy, 19(1):65-79.

Doganoglu, T. ve Wright, J. (2006) "Multihoming And Compatibility" International Journal of Industrial Organization, 24(1):45-67.

Frank, L.D. (2004) "An Analysis of the Economic Situation on Modeling and Forecasting The Diffusion of Wireless Communications in Finland" Technological Forecasting and Social Change, 71:391-403.

Gamboa, L.F. ve Otero, J. (2009) "An Estimation of the Pattern of Diffusion of Mobile Phones: The Case of Colombia" Telecommunications Policy, 33: 611-620.

Geroski, P.A. (2000) "Models of Technology Diffusion" Research Policy, 29(4-5):603-625.

Golder, P.N. ve Tellis, G.J. (2004) "Going, Going, Gone: Cascades, Diffusion and Turning Points of the Product Life Cycle" Marketing Science, 23(2):207-218.

Griliches, Z. (1957) "Hibryd Corn: An Exploration in the Economics of Technological Change" Econometrica, 25(4):501-522.
Gruber, H. ve Verboven, F. (2001) "The Diffusion of Mobile Telecommunications Services in The European Union" European Economic Review, 45(3):577-588.

Gruber, H. (2005) The Economics of Mobile Telecommunications, Cambridge, Cambridge University Press.

ICTA. (2012). Quarterly Market Data Report. Ankara: ICTA.

Jain, D.C ve Rao, R.C. (1990) "Effect of Price on the Demand for Durables: Modeling, Estimation, and Findings" Journal of Business \& Economic Statistics; 8(2):163-170.

Knudson, M.K. (1991) "Incorporating Technological Change in Diffusion Models" American Journal of Agricultural Economics; 73(3):724-733.

Lee, M. ve Cho, Y. (2007) "The Diffusion of Mobile Telecommunications Services in Korea" Applied Economics Letters, 14:477-481.

Lekvall, P. ve Wahlbin, C. (1973) "A Study of Some Assumptions Underlying Innovation Diffusion Functions" The Swedish Journal of Economics; 75(4):362377.

Mahajan, V. E. ve Muller E. (1979) "Innovation Diffusion and New Product Growth Models In Marketing" Journal of Marketing; 43(4):55-68.

Mahajan, V., Muller, E. ve Bass, F.M. (1990) "New Product Diffusion Models in Marketing: A Review and Directions for Future Research" Journal of Marketing; 54(1):1-26.

Mahajan, V.E. ve Peterson, R. (1985) Models for innovation diffusion, Beverly Hills, CA Sage Publications.

Mansfield, E. (1961) "Technical Change and The Rate of Imitation” Econometrica, 29(4): 741-766.

Meade N. ve Islam T. (1998) "Technological Forecasting: Model Selection, Model Stability, And Combining Models" Management Science, 44(8):111530.

Meade, N. ve Islam, T. (2001) "Forecasting The Diffusion of Innovations: Implications for Time Series Extrapolation" Armstrong, J.S (eds.) Principles of Forecasting: A Handbook for Researchers and Practitioners, Dordrecht, Kluwer Academic Publishers.

Meade, N. ve Islam, T. (2006) "Modelling and Forecasting The Diffusion of Innovation-A 25-Year Review" International Journal of Forecasting, 22(3):519545. 
Michalakelis, C., Varoutas, D. ve Sphicopoulos, T. (2008) "Diffusion Models of Mobile Telephony in Greece” Telecommunications Policy, 32:234-245.

Pilat, D. (2003) ICT and Economic Growth: Evidence from OECD Countries, Industries and Firms, Paris, OECD Publications.

Roderick, F. ve Preston, P. (1999) “The LongRun Diffusion and Techno-Economic Performance of National Telephone Networks: A Case Study of Ireland, 1922-1998" Telecommunications Policy; 23(5): 437-457.

Roller, L.H. ve Waverman, L. (2001) "Telecommunications Infrastructure and Economic Development: A Simultaneous Approach" American Economic Review, 91(4):909-923.

Rouvinen, P. (2006) "Diffusion of Digital Mobile Telephony: Are Developing Countries Different?" Telecommunications Policy, 30:46-63.
Srinivasan, V. ve Mason, C.H. (1986) "Nonlinear Least Squares Estimation of New Product Diffusion Models" Marketing Science, 5(2):169-178.

Su, Y. ve Han L. (1998) "A New Literature Growth Model: Variable Exponential Growth Law of Literature" Scientometrics, 42(2):259-265.

Sundqvist, S., Frank, L. ve Puumalainen, K. (2005) "The Effects of Country Characteristics, Culture Similarity and Adoption Timing on the Diffusion of Wireless Communications" Journal of Business Research, 58:107-110.

Van den Bulte, C. and Lilien, G. L. (1997). Bias and systematic change in the parameter estimates of macrolevel diffusion models. Marketing Science; 16(4): 338353.

Wu, F. ve Chu, W. (2010) "Diffusion Models of Mobile Telephony" Journal of Business Research, 63:497501. 